\title{
Use of SD-OCT to Quantitatively Evaluate Peripheral Congestion in Diastolic Dysfunction with a Role Model in Hemodialysis Patients with End-Stage Renal Disease.
}

Ibrahim Ozdemir ( $\sim$ dr.ibrahimozdemir@gmail.com )

Sakarya Yenikent State Hospital https://orcid.org/0000-0001-7195-8353

Süleyman Çağan Efe

Istanbul Dr Lufti Kirdar Kartal Egitim ve Arastirma Hastanesi

\section{Research Article}

Keywords: end stage renal disease, diastolic dysfunction, choroidal thickness, ultrafiltration rate

Posted Date: March 16th, 2021

DOl: https://doi.org/10.21203/rs.3.rs-307301/v1

License: (a) (i) This work is licensed under a Creative Commons Attribution 4.0 International License. Read Full License 


\section{Abstract}

Purpose: There is no practical quantitative tool to assess peripheral congestion in patients with congestive heart failure. In this study, we aimed to evaluate peripheral congestion by measuring choroidal thickness with SD-OCT in patients with end stage renal disease(ESRD). In addition, volume management by hemodialysis (HD) is often difficult in patients with ESRD. Volume overload or hypovolemia may increase morbidity and mortality in long-term HD patients. Therefore, it is important to determine the ideal ultrafiltration rate (UFR) for each patient. Also, we aimed to find a data to help determine the ideal UFR.

Methods: Fifty HD patients with ESRD were divided into 3 groups according to diastolic functions. Patients with mild diastolic dysfunction were enrolled in Group1, those with moderate diastolic dysfunction were enrolled in Group 2, and those with severe diastolic dysfunction were enrolled in Group 3. Choroid was used to evaluate peripheral congestion and choroidal thickness (CT) was measured by optical coherence tomography (OCT) before and after HD.

Results: The average CT before HD in Group $3(259.3 \pm 7.5 \mu \mathrm{m})$ was significantly higher than in Group 1 $(249.6 \pm 9.4 \mu \mathrm{m})(p=0,015)$. The average CT after HD in Group $3(224.1 \pm 5.2 \mu \mathrm{m})$ was significantly higher than in Group $1(232.4 \pm 9.3 \mu \mathrm{m})(\mathrm{p}=0,033)$. The mean of DCT was significantly higher in Group 3 than in Group $1(p<0.001)$

Conclusion:DCT was correlated with diastolic function in ESRD patients undergoing HD, and further evaluation of diastolic function before HD may play a role in finding the ideal UFR.

\section{Introduction}

Until now, peripheral congestion-edema is evaluated by pressing-pushing the pretibial area and graded between 0 and 4 according to the physician's experience. Moreover, this method is subjective.

End-stage renal disease (ESRD) is permanent irreversible loss of renal function. Patients with ESRD have a deficiency in removing uremic substances and water from body. Thus, the hemodialysis (HD) is used to control the body volume and composition by removal of water and uremic substances [1]. But, volume management is often difficult in HD patients with ESRD. It remains a mystery to assess the volume status and decide how much fluid to take during HD, called the ultrafiltration rate (UFR)[2].

Choroid is a highly vascularized cavernous tissue and choroid vascular resistance is low. Thus, the choroidal vascular circulation flow is very high. In addition, perfusion pressure affects the blood flow directly because the choroid is poorly autoregulated[3,4]. Therefore, the choroid can be easily affected by systemic diseases $[5,6]$. In Inter-dialytic period, volume overload negatively affects diastolic function[7]and causes a decrease in venous return. And increased volume load with reduced venous return leads to the accumulation of fluid in tissues such as choroid. Previous studies showed that choroid thickness changes before and after $\mathrm{HD}[4,8,9]$.

In this study, ESRD patients who underwent HD were grouped according to their diastolic functions. Choroidal thickness (CT) measured by SD-OCT was aimed toevaluate the peripheral congestion. We also 
aimed to evaluate the importance of the diastolic function in calculating the UFR. Therefore, this study is different from previous similar studies.

\section{Materials And Method}

This study was planned retrospectively. Sixty seven patients with ESRD undergoing HD in hemodialysis unit of the Ağrı State Hospital were included to this study between 2014-2017.

The study conformed the tenets of the Declaration of Helsinki and also it was approved by local ethical committee (ID:71522473/050.01.04/197). The inclusion criteria was availability of OCT images with highquality.

Based on transthoracic echocardiogram, patients having diastolic dysfunction with preserved systolic function (EF>50\%) were included. On the basis of the hemodialysis method, patients who underwent hemodialysis sessions three times a week for more than five years were included. The exclusion criteria were as follows: the presence of any glaucomatous and retinal diseases except diabetic retinopathy, such as macular hole, epiretinal membrane, degenerative myopia, age-related macular degeneration, or macular edema of any origin.

Sixty seven patients met the study criteria. Seventeen patients were excluded because of normal diastolic function (9 patients), unavailability of OCT images (5 patients), macular edema (2 patients) and degenerative myopia (2 patient). The patients were divided into three groups according to diastolic dysfunction. Diastolic function grading was assigned based on current guidelines[10]. Group 1 was composed of patients with mild diastolic dysfunction $(n=20)$, Group 2 was composed of patients with moderate diastolic dysfunction $(n=20)$ and Group 3 was composed of patients with severe diastolic dysfunction $(n=10)$.

The patients underwent 3-h to 4-h hemodialysis sessions three times per week, using a high-performance dialyzer at a blood flow rate of $250 \mathrm{~mL} / \mathrm{min}$. The standard dialysate flow rate was $500 \mathrm{~mL} / \mathrm{min}$.

A detailed ophthalmological examination was performed before and two to three hours after HD, including slit-lamb bio-microscopy, fundus examination, and OCT imaging. In selected cases, fundus angiography was used. All patients were examined by the same ophthalmologist (IO).

OCT was performed using the 3D OCT 2000 FA Plus Spectral Domain (Topcon Medical Systems, Inc. Tokyo, Japan), which has a 840 -nm wavelength light source, 5- $\mu$ m axial image resolution, and speed of 27,000 Ascans per second. CT was measured using a single $9-\mathrm{mm}$ horizontal line scan through the center of the fovea with 1024 A-scan/B-scan captured 50 times in the same position and overlapped with 50 B-scan images by the OCT device software $(9 \mathrm{~mm} \times 0,15 \mathrm{~mm}, 1024 \times 50$ voxels). The enhanced choroidal mode was used to get a fine focus of the choroidal structure. B-scan images with low quality and indistinctive choroidal-scleral boundary were rejected. The eye that had a higher quality B-scan image was used for measurement. B-scan scale was adjusted to $1: 1 \mathrm{~mm}$ and image size was doubled up. CT was described as the vertical distance between the outer edge of the hyperreflective retinal pigment epithelium and the scleral 
boundary and was manually measured at the fovea centralis by the same ophthalmologist using "'built-in caliper" in the linear measurement tools of the OCT device software.

Transthoracic echocardiograms were completed according to echocardiography laboratory protocol by same cardiologist (SCE). Images were analyzed investigators with remeasurement of all relevant parameters.

These included left atrial volume measurements, peak early $(e)$ and atrial (a) velocities of mitral inflow, early mitral inflow deceleration time (DT), septal and lateral mitral annular $e^{\prime}$ velocities. Each measurement was averaged over multiple cardiac cycles. Diastolic function grading was assigned based on current guidelines[10].

Data was statistically analyzed of using the SPSS statistical package version 25.0 (SPSS Inc., Chicago, IL, USA). The Kolmogorov-Smirnov test was used to assess the normal distribution of range of CT, e, a, e', e/a and $e / e^{\prime}$. Levene's test was used to assess variance homogeneity of the variables. Chi Square test and Kruskal Wallis test were used to evaluate the significance of differences between the groups. The choroidal change $(\triangle \mathrm{CT})$ was defined by the formula: $\triangle \mathrm{CT}=$ [CT after hemodialysis] -[CT before hemodialysis]. Additionally, the relationship between the range of $\mathrm{CT}$ and $e / a$ was assessed using the Spearman rank correlation test. The value of statistical significance was set at $P<0.05$.

\section{Results}

This study comprised 20 patients (female, 12; male, 8) in Group 1, 20 patients (female, 8; male, 12)in Group 2, and 10 patients (female, 4; male, 6 ) in Group 3. The mean age \pm SD of patients in Group 1 was $57.6 \pm 9.9$ years, in Group 2 was $47.8 \pm 18.3$ years and in Group 3 was $56.8 \pm 11.6$ years, respectively [Table 1]. The causes of patients with ESRD in the study were DM $(n=34)$; high blood pressure $(n=6)$; urinary tract dysfunction $(n=5)$; chronic glomerulonephritis $(n=4)$; and polycystic kidney disease $(n=1)$.

The average CT before HD was $249.6 \pm 9.4 \mu \mathrm{m}, 250.8 \pm 7.6 \mu \mathrm{m}$ and $259.3 \pm 7.5 \mu \mathrm{m}$ in the Group 1, Group 2, and Group 3, respectively. The average CT after HD was $232.4 \pm 9.3 \mu \mathrm{m}, 225.8 \pm 8.5 \mu \mathrm{m}$ and $224.1 \pm 5.2 \mu \mathrm{m}$ in the Group 1, Group 2 and Group 3, respectively. The mean of $\Delta$ CTwas $17.2 \pm 8.7 \mu \mathrm{m}, 24.9 \pm 5.3 \mu \mathrm{m}, 35.2 \pm$ $5.2 \mu \mathrm{m}$ in the Group 1, Group 2 and Group 3, respectively. It was significantly higher in Group 2 than in Group $1(p=0.023)$ and significantly higher in Group 3 than in Group $2(p=0.021)$ [Table 2].

The $e, e^{\prime}, a, e / a$ and $e / e$ were used to evaluate diastolic dysfunction. Therefore, these values were used to group patients according to diastolic dysfunction. The average $e$ was $0.74 \pm 0.21,0.95 \pm 0.17,1.16 \pm 0.20$ in the Group 1, Group 2 and Group 3, respectively. The average $a$ was $0.94 \pm 0.19,0.78 \pm 0.12,0.71 \pm 0.82$ in the Group 1, Group 2 and Group 3, respectively. The average e/a was $0.79 \pm 0.16,1.23 \pm 0.16,1.62 \pm 0.15$ in the Group 1, Group 2 and Group 3, respectively. The average e/a was significantly higher in Group 2 than in Group $1(p<0.001)$ and significantly higher in Group 3 than in Group2 $(p=0.018)$. The other parameters are summarized in Table 2. Additionally, the $\triangle C T$ was positively correlated with the $e / a(r=0.570, p<0.0001)$.

\section{Discussion}


Peripheral congestion in ESRD patients with preserved ejection fraction could be affected by diastolic function.Therefore, unlike other studies, we grouped patients according to their diastolic function using ECO. In this study, although pre-HD CT was significantly high in patients with severe diastolic dysfunction $(p=0,015)$ and the same amount of fluid was taken by the HD, these patients with severe diastolic dysfunction had significantly more reduction in post-HD CT than patients with mild diastolic dysfunction $(p=0,033)$. In other words,although the same amount of body fluid was extracted by HD (same UFR), the $\triangle C T$ was significantly higher in severe diastolic dysfunction group than in mild diastolic dysfunction group ( $\mathrm{p}<$ $0.001)$. Moreover, the $\Delta C T$ was different in each group according to diastolic function $(r=0.570, p=$ $0.0001 ; p<0.001)$. The $\Delta C T$ in group 2 was significantly higher than group $1(p=0.023)$ and the $\triangle C T$ in group 3 was significantly higher than group $2(p=0.021)$. In patients with preserved left ventricular ejection fraction, diastolic dysfunction causes an increase in end diastolic pressure, resulting in systemic congestion or insufficiency. The severity of this congestion can be determined by the severity of diastolic dysfunction. In present study, the diastolic function before HD was significantly correlated with $\Delta C T(r=0.570, p=0.0001)$. This indicates that peripheral volume overload can be misleading in the presence of diastolic dysfunction. It also suggests that low UFR may be administered to get similar treatment response between patients with severe diastolic dysfunction and patients with mild diastolic dysfunction.

The choroid is vascularized and cavernous tissue with a low vascular resistance [3,11], so it can be easily affected by various ocular and systemic conditions $[4,5,6,12,13]$. For example, it was reported that the water drink test (1000 mL water intake in a short time) caused a significant increase in choroid thickness in healthy individuals [13]. This situation is similar to the patient with ESRD in the inter-dialytic period. In the inter-dialysis period, increased vascular hydrostatic pressure due to volume overload and decreased osmotic pressure due to volume overload may cause fluid to accumulate in the choroid interstitial space. HD provides the opposite of this situation, as a result, choroidal vascular volume and interstitial fluid volume decrease. Recent studies have shown that CT decreases after HD in patients with ESRD by using OCT[4,8,9]. Akihiro et al. [9]grouped patients with ESRD diabetic and non-diabetic, and found that CT decreased in all eyes after HD. The mean CT values before and after hemodialysis were $268 \mu \mathrm{m}$ and $234 \mu \mathrm{m}$,similar to our results[9]. The $\Delta C T$ was also evaluated, and the $\triangle C T$ in the diabetic group was higher than in the non-diabetic group. In this study, the $\triangle C T$ in all patients was similar with diabetic group. Because the majority of our patients were ESRD patients due to diabetes. In the light of the above data[4,5,6,12,13], the choroid may be considered as a region of congestion under volume overload in patients with ESRD. Moreover, the choroid can be quantitatively evaluated by ОСТ [14].

In patients with ESRD, diastolic dysfunction is associated with high-left ventricular hypertrophy (LVH) as well as volume overload[15,16]. It is known that LVH is very common in ESRD patients and left ventricular mass index gradually increases after the start of $\operatorname{HD}[16,17]$. Therefore, diastolic dysfunction is common in ESRD patients and is a more common mechanism of heart failure than reduction of the ejection fraction in patients with ESRD[15,16]. But the number of studies associated with diastolic dysfunctionin patients with ESRD is low. Mostly, the effect of dialysis on left ventricular function or left ventricular hypertrophy was investigated. In present study, left ventricular function was not evaluated. 
Volume management in patients with ESRAD involves monitoring weight gains between HD sessions. In general, the weight gain between two HD sessions should be less than $1.5 \mathrm{~kg}$ (or $<20 \mathrm{ml} / \mathrm{kg}$ ). High IDWG, more food intake and a strong appetite will often lead to increased UFR in the next HD.Or, low inter-dialytic weight gain, poor intake, diminished appetite and diarrhea require less fluid removal in the next HD session[2]. When adjusting UFR, the patient's symptoms or morbid conditions and physical examination findings should also be considered. For example; high pre-HD systolic blood pressure (e.g., > 160 mmHg), pulmonary edema, lower extremity and sacral edema may suggest volume overload or low UFR. Conversely, low pre-HD systolic blood pressure (e.g., < $120 \mathrm{mmHg}$ ), tachycardia, palpitation, chest pain, lightheadedness, cramps, sweating towards after HD session may suggest hypovolemia or high UFR[2,18]. Based on the above information, a patient with severe diastolic dysfunction giving symptoms and signs of volume overload may be administered high UFR for a long time. High body fluid removal in patients with severe diastolic dysfunction may increase morbidity and mortality.

This study is limited by its retrospective nature and shares all the limitations of a retrospective study and represents a relatively small sample size in groups. Our SD-OCT device cannot give you the chance to create a $3 \mathrm{D}$ virtual image and measure the entire choroid volume. Furthermore, we aimed to associate the $\triangle \mathrm{CT}$ with diastolic dysfunction change, but after HD it was not possible to evaluate diastolic function due to poor visibility of ECO. If we could associate the $\triangle \mathrm{CT}$ with the diastolic function change, the correlation rate could be higher than 0.570 . A prospective, randomized longitudinal study would allow to get more precise result.

Choroidal thickness measured by OCT can be used as a quantitative tool to assess peripheral congestion. Additionally, in ESRD patients with diastolic dysfunction, assessing the diastolic function periodically may help to estimate the each patient's volume status and may help to find ideal UFR for each patients.

\section{Declarations}

Ethical Rules: The author has taken these ethical rules by Sakarya Universityat 2020 (ID: 71522473 / 050.01.04 / 197) to prepare, write and publish.

Author contribution: Both authors collected the data together. IO did the statistics and writing of the article.

Data sharing: No additional data.

Funding: No funding.

Competing interest: The authors report no conflicts of interest.

Funding: No funding.

Competing interest: The authors report no conflicts of interest.

The contents of the article was not presented at a conference

Correspondence author and address: 
Ibrahim Ozdemir,

Yenikent State Hospital, Department of Ophthalmology, Sakarya, Turkey

Tel: 0090 264- 2213500,

Fax: 0090 264- 2213500.

\section{References}

1-Leypoldt JK, Cheung AK, Delmez JA, et al. Relationship between volume status and blood pressure during chronic hemodialysis. Kidney Int 2002;61:266-75.

2- J.A. Chou, K. Kalantar-Zadeh. Volume Balance and Intradialytic Ultrafiltration Rate in the Hemodialysis Patient. Curr Heart Fail Rep. 2017 Oct;14(5):421-427

3- Delaey C, Van De Voorde J. Regulatory mechanisms in the retinal and choroidal circulation. Ophthalmic Res 2000;32:249-56.

4- Shin YU, Lee SE, Kang MH, Han SW, Yi JH, Cho H.Evaluation of changes in choroidal thickness and the choroidal vascularity index after hemodialysis in patients with end-stage renal disease by using sweptsource optical coherence tomography. Medicine (Baltimore). 2019 May;98(18):e15421

5- Gök M, Karabaş VL, Emre E. et al.Evaluation of choroidal thickness via enhanced depth-imaging optical coherence tomography in patients with systemic hypertension. Indian J Ophthalmol. 2015 Mar;63(3):239-43

6- Altinkaynak H, Kara N, Sayın N, Güneş H, Avşar S, Yazıcı AT. Subfoveal choroidal thickness in patients with chronic heart failure analyzed by spectral-domain optical coherence tomography.Curr Eye Res. 2014 Nov;39(11):1123-8.

7- Smyth B, Chan CT, Grieve SM, Puranik R, Zuo L, Hong D6 et al. Predictors of change in left-ventricular structure and function in a trial of extended hours hemodialysis.J Card Fail. 2020 Apr 14. pii: S10719164(19)31786-5

8-Jung JW, Chin HS, Lee DH, Yoon MH, Kim NR.Changes in subfoveal choroidal thickness and choroidal extravascular density by spectral domain optical coherence tomography after haemodialysis: a pilot study.Br J Ophthalmol. 2014 Feb;98(2):207-12.

9- Ishibazawa A, Nagaoka T, Minami Y, Kitahara M, Yamashita T, Yoshida A. Choroidal Thickness Evaluation Before and After Hemodialysis in Patients With and Without Diabetes. Invest Ophthalmol Vis Sci. 2015 Oct;56(11):6534-41

10- Nagueh SF, Smiseth OA, Appleton CP et al. Recommendations for the Evaluation of Left Ventricular Diastolic Function by Echocardiography: An Update from the American Society of Echocardiography and the European Association of Cardiovascular Imaging. J Am SocEchocardiogr. 2016 Apr;29(4):277-314. 
11- Alm A, Bill A. Ocular Circulation. 9th ed. St. Louis: Mosby; 1992.

12- Schuster AK, Leuschner A, Feretos $\mathrm{C}$ et al.Choroidal thickness is associated with cardiovascular risk factors and cardiac health: the Gutenberg Health Study.Clin Res Cardiol. 2020 Feb;109(2):172-182

13-Mansouri K, Medeiros FA, Marchase N, Tatham AJ, Auerbach D, Weinreb RN. Assessment of choroidal thickness and volume during the water drinking test by swept-source optical coherence tomography. Ophthalmology. 2013;120:2508- 2516.

14- Ikuno Y, Maruko I, Yasuno Y, et al. Reproducibility of retinal and choroidal thickness measurements in enhanced depth imaging and high-penetration optical coherence tomography. Invest Ophthalmol Vis Sci 2011;52:5536-40.

15-Malik J, Kudlicka J, Valerianova A, Kovarova L, Kmentova T, LachmanovaJ.Diastolic dysfunction in asymptomatic hemodialysis patients in the light of the current echocardiographic guideline.Int $\mathrm{J}$ Cardiovasc Imaging. 2019 Feb;35(2):313-317

16- Antlanger $\mathrm{M}$ et al (2017) Heart failure with preserved and reduced ejection fraction in hemodialysis patients: prevalence, disease pre- diction and prognosis. Kidney Blood Press Res 42(1):165-176

17- Dolan M, Whipp B, Wasserman K, Davidson W Cause of hypoxemia during hemodialysis. (1981) N Engl J Med 305(22):1351-1352

18- Park J, Rhee CM, Sim JJ, et al. A comparative effectiveness research study of the change in blood pressure during hemodialysis treatment and survival. Kidney Int. 2013;84:795-802.

\section{Tables}

Table1: Demographics of patients

\begin{tabular}{|lccccc|}
\hline & $\begin{array}{c}\text { Patients with mild } \\
\text { diastolic dysfunction } \\
\text { Gruop1 }\end{array}$ & $\begin{array}{c}\text { Patients with moderate } \\
\text { diastolic dysfunction } \\
\text { Group2 }\end{array}$ & $\begin{array}{c}\text { Patients with severe } \\
\text { diastolic dysfunction }\end{array}$ & $\begin{array}{l}\text { All } \\
\text { patients }\end{array}$ & $\begin{array}{l}P \\
\text { value }\end{array}$ \\
Sex & $12 / 8$ & $8 / 12$ & $4 / 6$ & $24 / 26$ & $0,382^{\mathrm{a}}$ \\
F & & & & $53.6 \pm 0$ \\
M & & $47.8 \pm 18.3$ & $56.8 \pm 11.6$ & 14.6 & $0,140^{\mathrm{b}}$ \\
\hline
\end{tabular}

F: female M: male ${ }^{a}$ : Chi Square test ${ }^{b}$ : Kruskal Wallis test

Table 2: Distribution of the variables by groups 


\begin{tabular}{|c|c|c|c|c|c|c|c|c|}
\hline & Group 1 & Group 2 & $3^{\text {Group }}$ & $\begin{array}{l}\text { All } \\
\text { patients }\end{array}$ & $\mathrm{p}^{\mathrm{a}}$ & $p^{b}$ & $\mathrm{p}^{\mathrm{c}}$ & $p^{g}$ \\
\hline $\begin{array}{l}\text { CT } \\
\text { before } \\
\text { HD }\end{array}$ & $249.6 \pm 9.4 \mathrm{~mm}$ & $\begin{array}{l}250.8 \pm 7.6 \\
\mathrm{~mm}\end{array}$ & $\begin{array}{l}259.3 \pm \\
7.5 \\
\mathrm{~mm}\end{array}$ & $\begin{array}{l}252.0 \pm \\
9.0 \\
\mathrm{~mm}\end{array}$ & 0.015 & NS & 0.046 & 0,015 \\
\hline $\begin{array}{l}\text { CT } \\
\text { after } \\
\text { HD }\end{array}$ & $\begin{array}{l}232.4 \pm 9.3 \\
\mathrm{~mm}\end{array}$ & $\begin{array}{l}225.8 \pm 8.5 \\
\mathrm{~mm}\end{array}$ & $\begin{array}{l}224.1 \pm \\
5.2 \\
\mathrm{~mm}\end{array}$ & $\begin{array}{l}228.1 \pm \\
8.9 \mathrm{~mm}\end{array}$ & 0.016 & NS & NS & 0,033 \\
\hline DCT & $17.2 \pm 8.7 \mathrm{~mm}$ & $\begin{array}{l}24.9 \pm 5.3 \\
\mathrm{~mm}\end{array}$ & $\begin{array}{l}35.2 \pm 5.2 \\
\mathrm{~mm}\end{array}$ & $\begin{array}{l}23.9 \pm \\
9.5 \mathrm{~mm}\end{array}$ & $\begin{array}{l}< \\
0.001\end{array}$ & 0.023 & 0.021 & $\begin{array}{l}< \\
0.001\end{array}$ \\
\hline e & $0.74 \pm 0.21$ & $0.95 \pm 0.17$ & $\begin{array}{l}1.16 \pm \\
0.20\end{array}$ & $\begin{array}{l}0.91 \pm \\
0.24\end{array}$ & $\begin{array}{l}< \\
0.001\end{array}$ & 0.019 & 0,122 & $\begin{array}{l}< \\
0.001\end{array}$ \\
\hline a & $0.94 \pm 0.19$ & $0.78 \pm 0.12$ & $\begin{array}{l}0.71 \pm \\
0.82\end{array}$ & $\begin{array}{l}0.83 \pm \\
0.17\end{array}$ & 0.001 & 0.032 & NS & 0.002 \\
\hline eç & $0.10 \pm 0.05$ & $0.08 \pm 0.02$ & $\begin{array}{l}0.09 \pm \\
0.01\end{array}$ & $\begin{array}{l}0.09 \pm \\
0.03\end{array}$ & NS & NS & NS & NS \\
\hline e/a & $0.79 \pm 0.16$ & $1.23 \pm 0.16$ & $\begin{array}{l}1.62 \pm \\
0.15\end{array}$ & $\begin{array}{l}1.13 \pm \\
0.35\end{array}$ & $\begin{array}{l}< \\
0.001\end{array}$ & $\begin{array}{c}< \\
0.001\end{array}$ & 0.018 & $\begin{array}{l}< \\
0.001\end{array}$ \\
\hline e / eç & $8.14 \pm 2.95$ & $12.30 \pm 2.28$ & $\begin{array}{l}13.6 \pm \\
1.24\end{array}$ & $\begin{array}{l}10.90 \pm \\
3.33\end{array}$ & $\begin{array}{l}< \\
0.001\end{array}$ & 0.001 & NS & $\begin{array}{l}< \\
0.001\end{array}$ \\
\hline
\end{tabular}

CT: Choroid thickness, HD: Hemodialysis NS: not significant 